\title{
Características dos doadores de córneas do Banco de Olhos de Cascavel: impacto do exame anti-HBc para hepatite B
}

\author{
Characteristics of corneal donors in the Cascavel Eye Bank: impact of the anti-HBc test for hepatitis B
}

Cesar Nobuo Shiratori ${ }^{1}$, Flávio Eduardo Hiral ${ }^{2}$, Elcio Hideo Sato ${ }^{2}$

\section{RESUMO}

Objetivos: Traçar o perfil dos doadores de tecidos oculares humanos na região de atuação do Banco de Olhos de Cascavel - Paraná (PR) e verificar o impacto da positividade da sorologia positiva para hepatite B (anti-HBC) no descartes dos tecidos oculares.

Métodos: Estudo do tipo transversal de dados do Banco de Olhos de Cascavel do período de março de 2006 a abril de 2007. Informações como idade, sexo, causa de óbito, tempo entre óbito e enucleação e resultados sorológicos de doadores foram coletadas. Dados foram agrupados para caracterização da população de estudo e distribuídos segundo positividade da sorologia para hepatite B (anti-HBC).

Resultados: A média de idade dos doadores foi de 54,2 $\pm 20,6$ anos e a maioria era do sexo masculino (64,7\%). Tempo médio entre óbito e enucleação foi de 3,8 $\pm 2,4$ horas, a principal causa de óbito foram doenças cardiovasculares (34,5\%). Positividade para os marcadores anti-HBc e HBsAg foi de $47,4 \%$ e 1,5\%, respectivamente, sendo os exames sorológicos para hepatite $B$ a maior causa de descarte dos tecidos oculares doados. Doadores com sorologia positiva para anti-HBc apresentaram maior média de idade comparados com doadores com sorologia negativa $(p<0,001)$. Somente $0,8 \%$ das doações apresentaram sorologia positiva para hepatite $C$. Não houve doações com sorologia para HIV positiva no período do estudo.

Conclusões: Implementação do Banco de Olhos de Cascavel aumentou significativamente a disponibilização de córneas para transplante no Estado do Paraná. A principal contraindicação para disponibilização de tecidos oculares foi a positividade na sorologia para anti-HBC. Estudos de biosegurança devem ser realizados a fim de investigar o potencial de transmissão da hepatite B de doadores positivos para esse marcador. A inclusão desses doadores como doações efetivas acarretaria maior disponibilização de tecidos para transplantes.

Descritores: Banco de olhos; Doenças da córnea; Transplante de córnea; Doadores de tecidos; Obtenção de tecidos e órgãos; Preservação de órgãos; Preservação de tecidos; Hepatite B/virologia; Antígenos de superfície da hepatite B; Controle de qualidade

\begin{abstract}
Purpose: To describe the characteristics of human ocular tissue donors from the Cascavel Eye Bank in the State of Paraná (PR) and investigate the impact of hepatitis $B$ serologic test positivity on discarded ocular tissues.

Methods: Cross-sectional study of data collected between March 2006 and April 2007 at the Cascavel Eye Bank. Information such as age, gender, cause of death, time between death and enucleation, and serologic tests results was collected. Data were used to characterize the study population and stratified according to hepatitis B (anti-HBC) status.

Results: Mean age of donors was $54.2 \pm 20.6$ years and a greater proportion of men $(64,7 \%)$ was observed. Mean time between death and enucleation was $3.8 \pm 2.4$ hours, cardiovascular diseases were the main cause of death (34.5\%). Positivity of anti-HBC and $\mathrm{HBSAg}$ tests was $47.4 \%$ and $1.5 \%$, respectively. Hepatitis $B$ was the main reason for discarding corneas. Donors whose serologic tests were positive for anti-HBC had higher mean age compared to those with negative tests $(p<0.001)$. Only $0.8 \%$ of all donations tested positive for hepatitis C and donors with positive HIV test were not seen in our study.

Conclusions: Activities of the Cascavel Eye Banksignificantly increased the availability of corneas for transplant in the State of Paraná. The main contraindication for availability of ocular tissues was positivity of serologic tests for anti-HBC. Biosafety studies should be performed in order to investigate the potential transmission of hepatitis $B$ virus for donors with positive tests for anti-HBC. The inclusion of these donors would increase the number of corneas available for transplant.
\end{abstract}

Keywords: Eye banks; Corneal diseases; Corneal transplantation; Tissue donors; Tissue and organ procurement; Organ preservation; Tissue preservation; Hepatitis B/Virologia; Hepatitis B surface antigens; Quality control

\section{INTRODUÇÃO}

0 primeiro transplante de córnea penetrante foi realizado com sucesso em 1905. Entretanto, cirurgias eram raras devido à baixa disponibilidade de tecidos humanos e dificuldades de técnica cirúrgica. Foi nesse período que surgiu a idéia da criação de um sistema de coleta, processamento e distribuição de tecidos oculares aos médicos que realizavam transplante. Em 15 de

Trabalho realizado no Banco de Olhos de Cascavel, Cascavel (PR), Brasil.

${ }^{1}$ Médico, Banco de Olhos de Cascavel, Cascavel (PR), Brasil.

${ }^{2}$ Médico, Departamento de Oftalmologia, Instituto da Visão, Universidade Federal de São Paulo UNIFESP - São Paulo (SP), Brasil.

Endereço para correspondência: Cesar Nobuo Shiratori. Rua Minas Gerais, 1.986 - Cascavel (PR) CEP 85812-035 - E-mail: cesar@hospitaldeolhos.com.br

Recebido para publicação em 05.02.2010

Última versão recebida em 23.11.2010

Aprovação em 25.11.2010 dezembro de 1944 no "Manhattan Eye, Ear and Throat Hospital" foi criado o primeiro banco de olhos dos EUA, pela iniciativa do jovem oftalmologista R. Townley Paton ${ }^{(1-2)}$.

Atualmente, a deficiência de doadores de órgãos é obstáculo universal e o fator mais importante na provisão de tecidos para transplante. First relatou que a deficiência de doadores de órgãos não é primariamente o resultado da falta de doadores, mas consequência da dificuldade de identificá-los, obter o consentimento da família e captar o órgão ou tecido em tempo hábi|(3).

Em muitos estados do Brasil, a falta de tecidos oculares e de Banco de Olhos capacitados para fornecer córneas em número e qualidade adequados para transplante ainda é uma realidade ${ }^{(4)}$.

Por esse motivo, a atuação dos Bancos de Olhos é de fundamental importância, seja na busca ativa de doadores, entrevista dos familiares, captação dos tecidos doados em tempo hábil e sua distribuição com padrão de qualidade ${ }^{(5)}$

O presente estudo tem como objetivo traçar o perfil dos doadores de tecidos oculares humanos na região de atuação do Banco de Olhos de Cascavel - Paraná (PR), pioneiro na captação e processamento de 
tecidos oculares nesta região, assim como verificar o impacto das sorologias para hepatite B (anti-HBc) sobre o total de doações e a disponibilização de tecidos oculares para transplante.

\section{MÉTODOS}

O presente estudo, do tipo transversal, foi realizado no Banco de Olhos de Cascavel. Dados foram coletados dos relatórios de doação de córneas. Informações como idade, sexo, causa de óbito e resultados sorológicos dos doadores foram obtidas no período de março de 2006 a abril de 2007.

A causa de óbito foi definida como principal causa de morte pelo atestado de óbito. Tempo entre óbito e enucleação foi calculado em horas. No momento da captação foi realizada a coleta de amostra de sangue para a realização de exames sorológicos obrigatórios. As amostras de sangue do doador foram enviadas a um laboratório terceirizado que enviava os resultados por via eletrônica. No Banco de Olhos de Cascavel são realizados rotineiramente os testes sorológicos HBsAg, anti-HBC, anti-HCV, anti-HIV1 e anti-HIV $2^{(5)}$.

Dados foram agrupados e descritos como médias \pm desvio padrão ou proporções. Dados também foram distribuídos conforme a positividade da sorologia para hepatite B (Anti-HBC) onde os grupos foram comparados.

Para análise estatística foram utilizados os testes t de Student para variáveis contínuas e o teste exato de Fisher para variáveis categóricas. Valores de p menores que 0,05 foram considerados estatisticamente significantes.

Este estudo foi aprovado pelo Comitê de Ética da Universidade Federal de São Paulo sob o protocolo CEP 0814/09.

\section{RESULTADOS}

Neste período de 13 meses (março de 2006 a abril de 2007), foram contabilizadas 481 doações. A idade média dos doadores foi de 54,2 $\pm 20,6$ anos (de 3 a 97 anos) e a grande maioria era do sexo masculino $(64,7 \%)$. O tempo médio entre o óbito e a enucleação foi de 3,8 $\pm 2,4$ horas. A principal causa de óbito foram doenças cardiovasculares $(34,5 \%)$, seguida pelas causas externas $(30,6 \%)$, neoplasias $(27,2 \%)$ e outras causas $(7,7 \%)$ (Tabela 1$)$.

O principal local de captação dos tecidos oculares foi a Capela Mortuária Municipal - Administração dos Cemitérios e Serviços Funerários de Cascavel (ACESC) (67,8\%), seguido pelo Instituto Médico-Legal (IML) (22,9\%), serviço de tanatopraxia (TANATO) $(7,9 \%)$ e outros (1,4\%) (Tabela 1).

Quanto às sorologias, 47,4\% dos doadores tiveram positividade para uma das sorologias para hepatite B (anticorpo anti-HBC), 1,5\% apresentaram sorologia positiva para antígeno HBsAg e menos de 1\% apresentaram sorologia para hepatite C. Menos da metade dos doadores apresentaram sorologia negativa $(48,2 \%)$ (Tabela 2). Não houve doações com sorologias positivas para HIV I e II.

Ao compararmos doadores que tiveram sorologia negativa com os de sorologia positiva para um marcador de hepatite B (anticorpo Anti-HBc), observamos uma maior média de idade entre doadores com sorologia positiva $(p<0,001)$. Houve também uma maior proporção de sorologias positivas em doadores provenientes da ACESC $(p=0,04)$. Não houve diferença estatisticamente significante entre outros fatores como sexo e causa de óbito (Tabela 1).

\section{DISCUSSÃO}

O Banco de Olhos de Cascavel (BOC) iniciou suas atividades em março de 2006, com a finalidade de suprir a deficiência de tecidos oculares para transplante na região oeste do Paraná. Atende a cidade de Cascavel, que conta atualmente com uma população de aproximadamente 285 mil habitantes, e a região sudoeste deste estado. Para isso, conta com equipe própria para a realização de entrevista das famílias de potenciais doadores e outra equipe para a realização de captação dos tecidos atuando junto aos hospitais da cidade, ACESC, Instituto Médico-Legal (IML) e serviço de tanatopraxia.

Antes da implementação do serviço do BOC, eram realizados em média 494 transplantes ao ano no estado do Paraná. Após o advento do BOC houve um aumento de $36 \%$ no número de transplantes de córneas realizados no estado(6).

Em relação à idade média dos doadores, ela apresentou-se semelhante a outros estudos nacionais e internacionais ${ }^{(7-8)}$. De acordo com as normas médicas de nosso Banco de Olhos, adotamos o limite inferior de idade como sendo 3 anos, sendo que em alguns Bancos de Olhos, chega-se a adotar a idade de 10 anos $^{(8)}$. Não adotamos limite superior de idade para a doação, uma vez que não há comprovação de que a idade avançada do doador esteja relacionada com a sobrevivência do enxerto(8). Transplantes de córneas realizados utilizando córneas doadoras com idade menores que 66 anos, não evidenciaram diferença na incidência de falência do enxerto quando comparadas com córneas de igual qualidade provenientes de doadores maiores que 66 anos de idade ${ }^{(9)}$.

O tempo médio entre a ocorrência do óbito e a captação do tecido ocular foi de 3,8 horas, semelhante ao estudo realizado no Banco de Olhos do Hospital São Paulo(7). Este tempo considera-se adequado, pois a grande maioria dos óbitos são comunicados ao BOC quando o doador já se encontra na ACESC ou IML. O maior tempo decorrido entre o óbito e a captação do tecido ocular aumenta a chance de alteração do epitélio e do endotélio corneano, sendo este um fator que pode comprometer a avaliação do tecido doado, chegando até a contraindicar o tecido para uso em transplantes ópticos ${ }^{(10-11)}$. Apesar deste fato, existem estudos que não mostram diferenças estatisticamente significantes entre a falência primária do botão corneano transplantado e o tempo de enucleação e preservação(8,11)

As principais causas de óbitos foram em primeiro lugar as doenças cardiovasculares, seguidas pelas causas externas e neoplasias. Observou-se distribuição semelhante em outros estudos ${ }^{(7)}$, com grande prevalência das causas externas refletindo a violência que se apresenta hoje em nossa sociedade.

Em relação ao local de captação dos tecidos oculares, $67 \%$ das captações foram realizadas na ACESC, particularidade esta que facilita o trabalho de entrevista das famílias e a concretização da doação, uma vez que praticamente todos os óbitos ocorridos na cidade de Cascavel passam pela ACESC, que é um serviço funerário municipalizado centralizado.

O índice de contraindicações para disponibilização de tecidos doados chegou a 51,8\% das doações, índice este superior a outros serviços nacionais ${ }^{(12)}$. Em um estudo em Minas Gerais, de um total de 1668 córneas doadas, 24\% foram captadas mas não utilizadas. Em $46 \%$ destas, a não utilização deveu-se à sorologia positiva do doador aos testes para HIV e hepatites B e $C^{(12)}$.

Em Cascavel, a principal contraindicação para a disponibilização dos tecidos para transplantes ocorreu por positividade para uma das sorologias da hepatite B (anti-HBC).

Os marcadores virais de hepatite $B$ mais utilizados na prática clínica para a triagem de doadores são: $\mathrm{HBsAg}$, anti-HBs, anti-HBc, HBeAg e anti-HBe, sendo que a Resolução RDC 67 de 30 de setembro de 2008, determina que sejam realizadas as sorologias para $\mathrm{HBsAg}$ e anti-HBC(5). Os testes sorológicos para anticorpo anti-HBc são de dois tipos: anti-HBC lgG e IgM. De rotina, são realizados os testes de detecção do anticorpo anti-HBc total. Os principais métodos de triagem utilizados na sua determinação são: hemaglutinação, radioimunoensaio, enzimaimunoensaio, quimioluminescência e mais recentemente as técnicas de biologia molecular. Estas técnicas podem aumentar a sensibilidade e a especificidade da detecção do vírus da hepatite $B$ em amostras clínicas ${ }^{(13)}$.

Existe um único estudo com evidências de transmissão de hepatite B por transplante de córnea, mas, nessa época não era realizado rotineiramente $\mathrm{o}$ teste de $\mathrm{HBsAg}^{(14)}$. 
Tabela 1. Características de doadores conforme sorologia para hepatite B (anti-HBc) no Banco de Olhos de Cascavel - PR

\begin{tabular}{|c|c|c|c|c|}
\hline & \multirow{2}{*}{$\begin{array}{l}\text { População total } \\
\qquad(n=481)\end{array}$} & \multicolumn{2}{|c|}{ Sorologia para hepatite B (anti-HBc)* } & \multirow[b]{2}{*}{ Valor de $\mathbf{p}^{* *}$} \\
\hline & & Negativa $(n=232)$ & Positiva $(n=228)$ & \\
\hline Idade, anos & $54,2 \pm 20,6$ & $50,2 \pm 22,7$ & $57,9 \pm 17,6$ & $<0,001$ \\
\hline Sexo, masculino & 64,7 & 68,1 & 59,6 & 0,06 \\
\hline Causa de óbito & & & & 0,28 \\
\hline Doença cardiovascular & 34,5 & 29,7 & 37,3 & \\
\hline Causas externas & 30,6 & 36,6 & 26,3 & \\
\hline Neoplasias & 27,2 & 25,8 & 25,9 & \\
\hline Outros & 7,7 & 7,9 & 10,5 & \\
\hline Origem & & & & 0,04 \\
\hline ACESC & 67,8 & 60,8 & 73,2 & \\
\hline IML & 22,9 & 27,6 & 19,3 & \\
\hline Tanato & 7,9 & 9,5 & 6,7 & \\
\hline Outros & 1,4 & 2,1 & 0,8 & \\
\hline
\end{tabular}

* = foram excluídos 21 indivíduos que apresentaram sorologia inconclusiva ou positiva para HCV ou HBsAg

** $=$ valor de p comparando sorologias negativa e positiva

Tabela 2. Perfil sorológicos dos doadores do Banco de Olhos de Cascavel - PR

\begin{tabular}{lcc}
\hline Sorologia & Frequência & Porcentagem (\%) \\
\hline Negativa & 232 & 48,2 \\
Hepatite B (anti-HBc) & 228 & 47,4 \\
Hepatite B (HBsAg) & 7 & 1,5 \\
Hepatite C & 4 & 0,8 \\
Inconclusivo & 10 & 2,1 \\
HIV & 0 & 0 \\
Total & 481 & 100 \\
\hline
\end{tabular}

O "Eye Bank Association of America" preconiza apenas a realização de HBsAg como método de triagem para a hepatite $B$, não incluindo em sua rotina o anti-HBC ${ }^{(15)}$. Especialistas questionam a adoção da sorologia anti-HBc para a triagem de córneas, devido à sua alta sensibilidade, mas baixa especificidade ${ }^{(16)}$.

Estudo realizado em Banco de Sangue da região de Cascavel evidenciou, entre doadores de sangue, que a positividade de sorologias anti-HBc é significativamente maior do que em outras regiões do estado do Paraná(13). Na região de Cascavel, a positividade variou de 33,8 a 33,1\% nos anos de 1995 e 1996, respectivamente, enquanto que em outras regiões do Paraná esta positividade variou de 3,8 a $12,6 \%$. Estudos americanos mostram prevalência de 1,3 a $4,6 \%$ de positividade entre doadores de sangue ${ }^{(17)}$. Nas doações de córneas, estudos internacionais relatam presença de sorologias positivas para hepatite $B$ variando de 0,92 a 3,0\% das doações ${ }^{(8,16)}$.

Estudando-se a presença de DNA do vírus (HBV-DNA) nas amostras de doadores de sangue do Banco de Sangue de Cascavel, chegou-se a um resultado demonstrando a inexistência de DNA do vírus da hepatite $B$ nos soros de doadores de sangue com sorologias anti-HBc positivo e HBsAg negativo. Este teste é o mais sensível e específico para determinar o potencial de infectividade do vírus da hepatite $\mathrm{B}^{(18)}$

Nas doações de córneas, estudos internacionais relatam presença de sorologias positivas para hepatite B variando de 0,92 a 3,0\% das doações ${ }^{(8,16)}$. Estudo recente, realizado no Banco de Olhos do Hospital São Paulo, mostrou uma positividade para hepatite B de $10,4 \%$ das doações no período de 2006 e $2007^{(19)}$. Em nosso serviço, quando se leva em consideração a presença concomitante de sorologias positivas para anti-HBc e HBsAg, este índice de positividade cai de $47,4 \%$ para $1,5 \%$, dentro da média de outros serviços internacionais ${ }^{(8,20)}$
A existência de exames sorológicos positivos somente para anti$\mathrm{HBC}$ acontecem em algumas situações como: testes falso positivo, hepatite aguda com recuperação total e hepatite crônica onde o HBsAg não se tornou positivo. Em teoria, estes casos não seriam portadores de vírus da hepatite $\mathrm{B}$, portanto não apresentariam risco de transmissão do vírus ao receptor ${ }^{(21)}$. A realização da sorologia para anti-HBs poderia ser útil na diferenciação de pacientes com hepatite $\mathrm{B}$ crônica daqueles que tiveram o desenvolvimento de imunidade contra o vírus.

\section{CONCLUSÃO}

Levando em consideração que o descarte de córneas devido a esta situação específica quase chega a metade das doações e levando em consideração que existem estudos que há baixo potencial de infectividade nestes casos, devemos levar em consideração um meIhor estudo sobre esta situação, inclusive sobre a transmissão do vírus da hepatite $B$ através das córneas. A inclusão desses doadores como doações efetivas acarretaria maior disponibilização de tecidos para transplantes.

A criação do BOC resultou em importante aumento na disponibilização de tecidos para transplantes de córneas no estado do Paraná, com consequente diminuição no tempo de espera na fila de transplantes.

\section{REFERÊNCIAS}

1. The Eye Bank for Sight Restoration. History. [home page on the Internet]. New York: 2005 [cited 2009 May 25]. Available from: http://www.eyedonation.org/history.html

2. Chu W. The past twenty-five years in eye banking. Cornea. 2000;19(5):754-65.

3. First MR. Transplantation in the nineties. Transplantation. 1992:53(1):1-11.

4. Brasil. Ministério da Saúde. [home page on the Internet]. Brasília: Ministério da Saúde; 2009 [citado 2009 Maio 25]. Disponível em: http://portal.saude.gov.br/portal/saude/

5. Ministério da Saúde. Agência Nacional de Vigilância Sanitária. Resolução nำ67, de 30 de setembro de 2008. Dispõe sobre o regulamento técnico para o funcionamento de Bancos de Tecidos oculares de origem humana [Internet]. 2008 [citado 2009 Maio 25]. Disponível em: http://bvsms.saude.gov.br/bvs/saudelegis/anvisa/2008/res0067_30_09_2008.html

6. Secretaria de Estado da Saúde do Paraná. Número total de transplantes por órgãos e córneas. [Internet]. 1997 [citado 2009 Jun 20]. Disponível em: http://www.saude.pr. gov.br/modules/conteudo/conteudo.php?conteudo=1371.

7. Adán CB, Diniz AR, Perlatto D, Hirai FE, Sato EH. Dez anos de doação de córneas no Banco de Olhos do Hospital São Paulo: perfil dos doadores de 1996 a 2005. Arq Bras Oftalmol. 2008; 71(2):176-81.

8. Patel HY, Brookes NH, Moffatt L, Sherwin T, Ormonde S, Clover GM, et al. The New Zealand National Eye Bank study 1991-2003: a review of the source and management of corneal tissue. Cornea. 2005;24(5):576-82.

9. Cornea Donor Study Investigator Group; Gal RL, Dontchev M, Beck RW, Mannis MJ, Holland EJ, et al. The effect of donor age on corneal transplantation outcome results of the cornea donor study. Ophthalmology. 2008(115):620-6.e.6. 
10. Van Meter WS, Katz DG, White H, Gayheart R. Effect of death-to-preservation time on donor corneal epithelium. Trans Am Ophthalmol Soc. 2005(103):209-22; discussion 222-4.

11. Hirai FE, Adan CB, Sato EH. Fatores associados à qualidade da córnea doada pelo Banco de Olhos do Hospital São Paulo. Arq Bras Oftalmol. 2009;72(1):57-61.

12. Saldanha BO, Oliveira RE Jr, Araujo PL, Pereira WA, Simão Filho C. Causes of nonuse of corneas donated in 2007 in Minas Gerais. Transplant Proc. 2009:41(3):802-3.

13. Largura MA, Pacheco M, Largura A. Ausência do HBV-DNA por PCR em soros de doadores de sangue com HBsAg negativo e anti-HBc positivo em região de alta prevalência de hepatite B. Rev Bras Anal Clin. 1998;30(3):141-6.

14. Hoft RH, Pflugfelder SC, Forster RK, Ullman S, Polack FM, Schiff ER. Clinical evidence for hepatitis B transmission resulting from corneal transplantation. Cornea. 1997;16(2):132-7. Comment in: Cornea.1997;16(2):123-4.

15. Eye Bank Association of America. Medical Standards [Internet]. Washington, DC: Eye Bank Association of America; 1995 [cited 2009 Jun 21]. Available from: www.restoresight.org

16. Mattern RM, Cavanagh HD. Should antibody to hepatitis B core antigen be tested in routine screening of donor corneas for transplant? Cornea. 1997;16(2):138-45. Comment in: Cornea. 1997;16(2):123-4.
17. AuBuchon JP, Sandler SG, Fang CT, Dodd RY. American Red Cross experience with routine testing for hepatitis B core antibody. Transfusion. 1989;29(3):230-2.

18. Douglas DD, Taswell HF, Rakela J, Rabe D. Absence of hepatitis B virus DNA detected by polymerase chain reaction in blood donors who are hepatitis $B$ surface antigen negative and antibody to hepatitis B core antigen positive from a United States population with a low prevalence of hepatitis B serologic markers. Transfusion. 1993; 33(3):212-6.

19. Viegas MT, Pessanha LC, Sato EH, Hirai FE, Adán CB. [Discarded corneas due to positive donor's serologic test in the Hospital São Paulo Eye Bank: a two-year study]. Arq Bras Oftalmol. 2009;72(2):180-4. Portuguese.

20. Mahalakshmi B, Madhavan HN, Pushpalatha R, Margarita S. Seroprevalence of human immunodeficiency virus, hepatitis B virus and hepatitis C virus among eye donors. Indian J Ophthalmol. 2004:52(1):61-2

21. Weinbaum CM, Williams I, Mast EE, Wang SA, Finelli L, Wasley A, Neitzel SM, Ward JW Centers for Disease Control and Prevention. Recommendations for identification and public health management of persons with chronic hepatitis B virus infection. MMWR Recomm Rep. 2008;57(RR-8):1-20. 